\title{
Grain and dendrite refinement of A356 alloy with Al-Ti-C-RE master alloy
}

\author{
Hong-Liang Zhao*, Jin-Sheng Yue, \\ Ya Gao, Kang-Rong Weng
}

Received: 22 February 2012/Revised: 11 June 2012 / Accepted: 15 June 2012/Published online: 21 February 2013

(C) The Author(s) 2013. This article is published with open access at Springerlink.com

\begin{abstract}
Commercial A356 alloy was refined with a homemade Al-5Ti-0.25C-2RE master alloy, and the microstructure and macrostructure of the refined alloy were investigated. The results show that the grain refining effect of A356 is poor by the addition level of $0.5 \mathrm{wt} \%$ master alloy, but when the level reaches $3.0 \mathrm{wt} \%$ the grain can get a satisfactory refining effect. Dendrite of A356 can be effectively refined by addition of $0.5 \mathrm{wt} \%$ master alloy; however, the refining effect is not significantly improved by further increasing the addition of master alloy. Grain and dendrite refining effects are compared in this article, and the results show that the grain and dendrite exhibit different refining effects with the same addition level of master alloy. Dendrite is easier to reach the optimal refining effect than grain.
\end{abstract}

Keywords Al-Ti-C-RE; A356; Grain refiner;

Secondary dendrite arm spacing (SDAS)

\section{Introduction}

Grain size and secondary dendrite arm spacing (SDAS) are two main standards for evaluating the refining effect of aluminum and its alloy. Grain refinement can not only improve the mechanical properties of alloys but also reduce its sensitivity of shearing stress and time of homogenization effectively and bring a series of excellent qualities to aluminum alloy $[1,2]$. As an important parameter in $\mathrm{Al}-\mathrm{Si}$ alloys, SDAS has a close relationship with alloy's

H.-L. Zhao*, J.-S. Yue, Y. Gao, K.-R. Weng

College of Materials Science and Engineering,

Zhengzhou University, Zhengzhou 450002, China

e-mail: zhlwkr@zzu.edu.cn mechanical properties, microsegregation, and the distribution of shrinkage porosity and many other microdefects [3, 4]. Therefore, fining dendrite structure and reducing the SDAS have a practical significance in improving the properties of alloys.

A356 alloys are most popular in the aeronautic and automotive industries. However, coarse grains and dendrite in A356 lead to low mechanism properties. Al-Ti-B master alloys are most commonly used in commercial A356, whereas $\mathrm{TiB}_{2}$ particles are easily aggregated in the melt and get poisoned by $\mathrm{Zr}, \mathrm{Cr}$, and $\mathrm{Mn}[5,6]$. Al-Ti-C was found to be free from the problems of Al-Ti-B, but the poor wettability between graphite and liquid aluminum made the fabrication and application of $\mathrm{Al}-\mathrm{Ti}-\mathrm{C}$ grain refiners become very difficult in industry [7]. In our previous experiments, a certain amount of RE was added in preparing $\mathrm{Al}-\mathrm{Ti}-\mathrm{C}$, and the poor wettability was successfully solved [8].

Some researchers stressed that the grain size was the weighting standard in evaluating the refining effect of $\mathrm{Al}-\mathrm{Si}$ alloys [7, 9], and others claimed SDAS was the criterion [1012], but the grain refinement and dendrite refinement were not considered simultaneously. In this article, commercial A356 alloy was refined with a homemade Al-5Ti-0.25C-2RE master alloy, and the microstructure and macrostructure of refined A356 alloys were observed and analyzed.

Grain refinement and dendrite refinement were evaluated, respectively, and the refining mechanism were also discussed.

\section{Experimental}

First, the commercial A356 alloy was placed into a graphite crucible and melted at $760{ }^{\circ} \mathrm{C}$ in a qualified resistance furnace. After the A356 alloy was fully melted, 

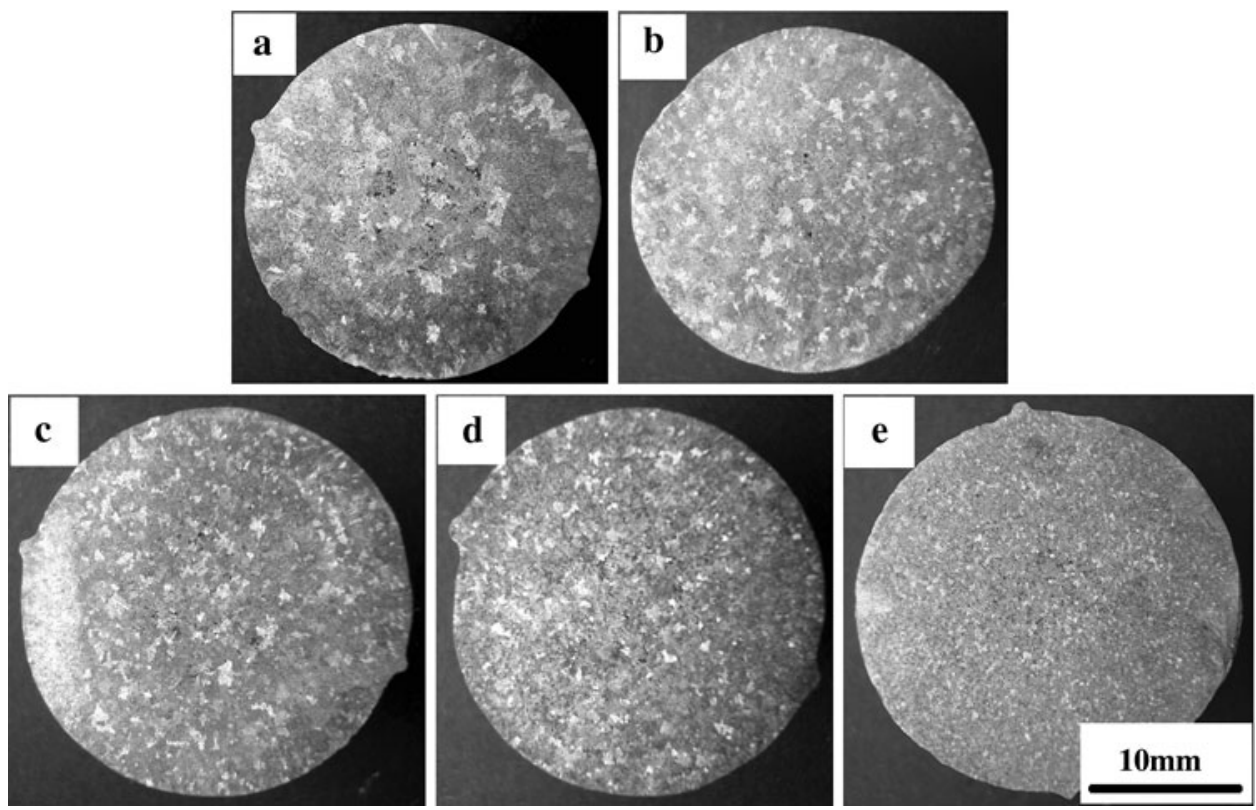

Fig. 1 Optical images of A356 with different addition levels of Al-5Ti-0.25C-2RE. a 0 wt $\%$, b 0.5 wt $\%$, c 1.0 wt $\%$, d 2.0 wt $\%$, and e 3.0 wt $\%$

Table 1 BH of the commercial A356

\begin{tabular}{llllll}
\hline Alloy & $\begin{array}{l}\text { A356 } \\
\text { alloy }\end{array}$ & $\begin{array}{l}\text { A356 }+0.5 \% \\
\text { Al-5Ti-0.25C-2RE }\end{array}$ & $\begin{array}{l}\text { A356 }+1.0 \% \\
\text { Al-5Ti-0.25C-2RE }\end{array}$ & $\begin{array}{l}\text { A356 + 2.0 } \% \\
\text { Al-5Ti-0.25C-2RE }\end{array}$ & $\begin{array}{l}\text { A356 + 3.0 } \% \\
\text { Al-5Ti-0.25C-2RE }\end{array}$ \\
\hline BH & 56.12 & 57.94 & 62.34 & 64.54 & 65.61 \\
\hline
\end{tabular}
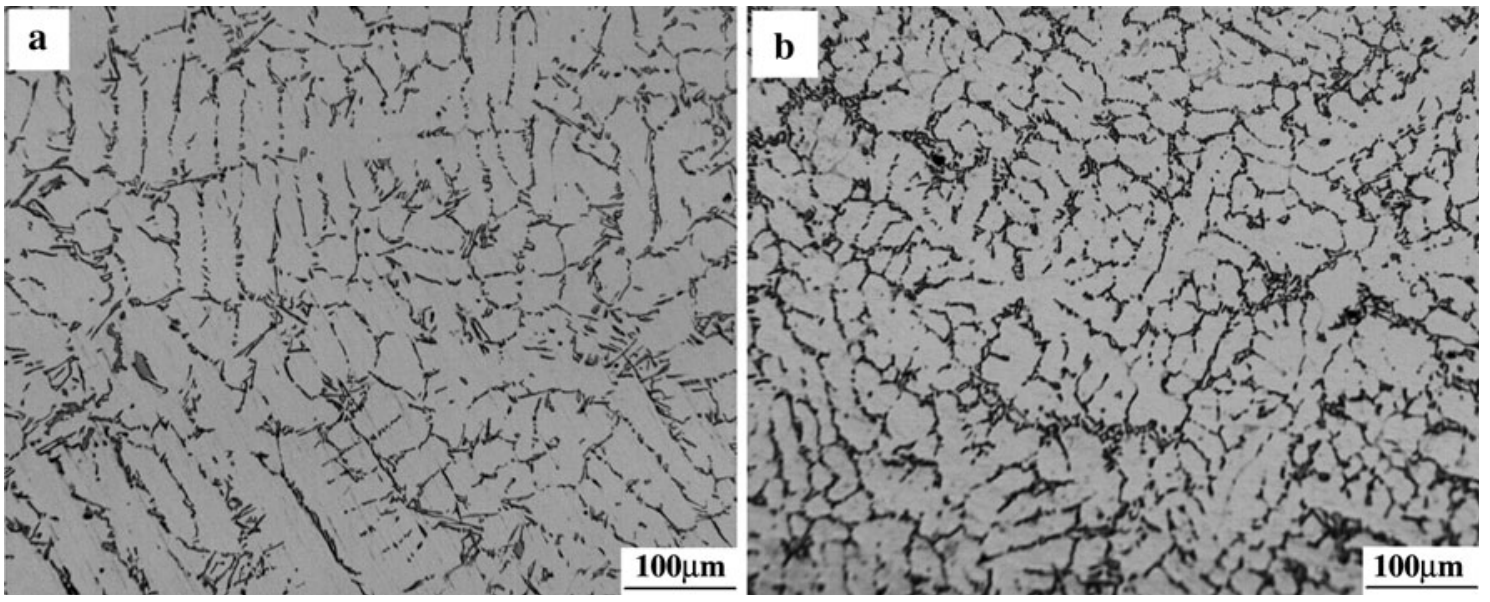

Fig. 2 a Microstructure of A356 without grain refiner and b A356 refined by Al-5Ti-0.25C-2RE

the temperature was decreased to $720^{\circ} \mathrm{C}$, and then a certain amount of Al-5Ti-0.25C-2RE master alloy was added into the melted A356; after holding for $3 \mathrm{~min}$, the melt was stirred slightly for $30 \mathrm{~s}$ to make sure the master alloy was dispersed uniformly into the melt. After holding for a certain time, the melt was poured into a cast iron mold at $720{ }^{\circ} \mathrm{C}$. The bar has a dimension of $\Phi 25 \mathrm{~mm} \times 100 \mathrm{~mm}$. Samples were cut at $45 \mathrm{~mm}$ from the bottom of the bar.
Macrospecimens were etched with a mixed acid of $60 \%$ $\mathrm{HCl}+30 \% \mathrm{HNO}_{3}+5 \% \mathrm{HF}+5 \% \mathrm{H}_{2} \mathrm{O}$. Microspecimens were grinded, polished, and etched with a reagent of $0.5 \mathrm{vol} \% \mathrm{HF}$, and then the microstructure was analyzed by optical microscopy. An image analysis software (Image J) was used in measuring and calculating the grain size and SDAS. The Brinell hardness (BH) of A356 alloys was tested by BH-A5 Brinell microhardness tester. 
a
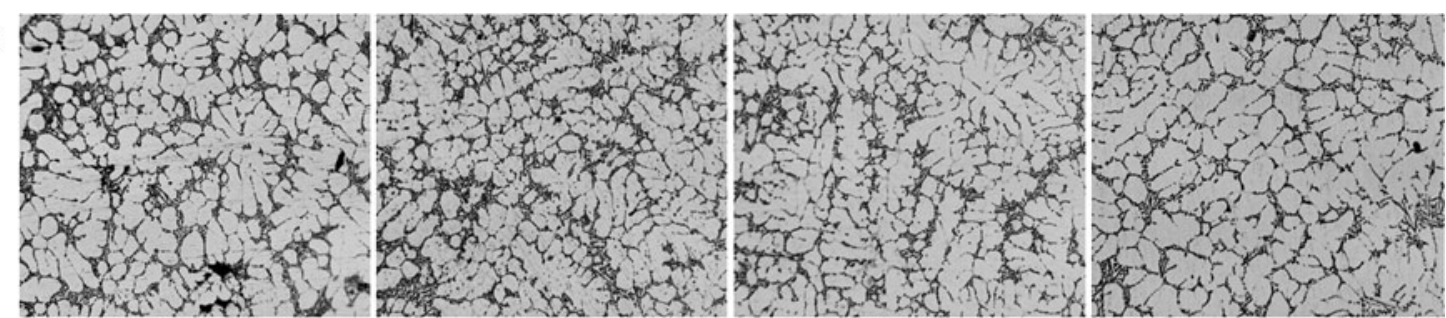

b
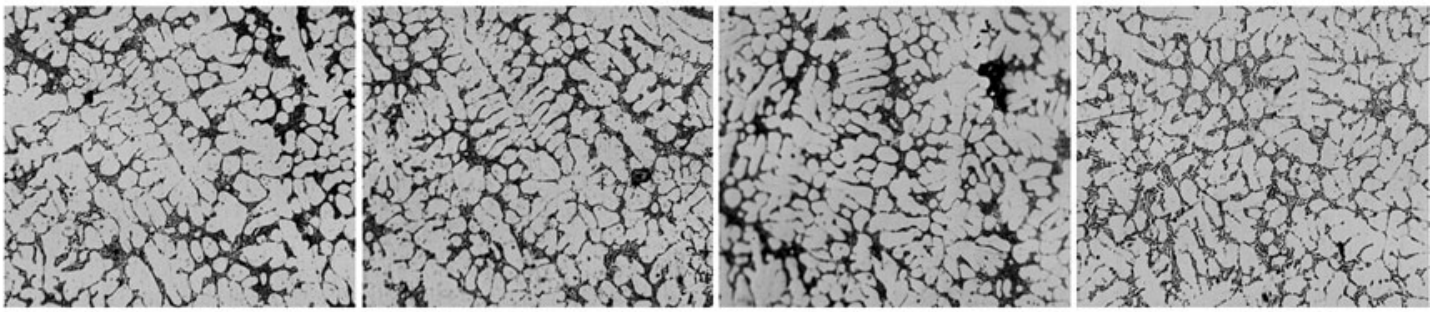

c
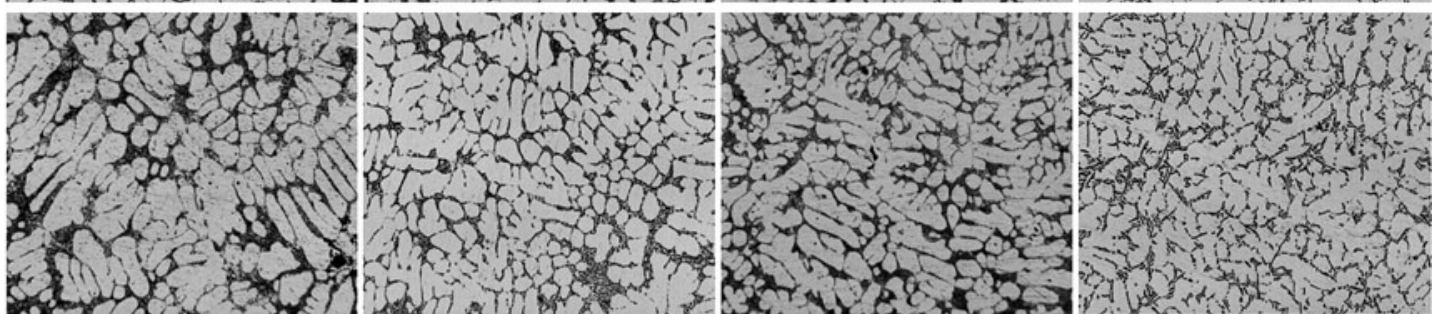

d
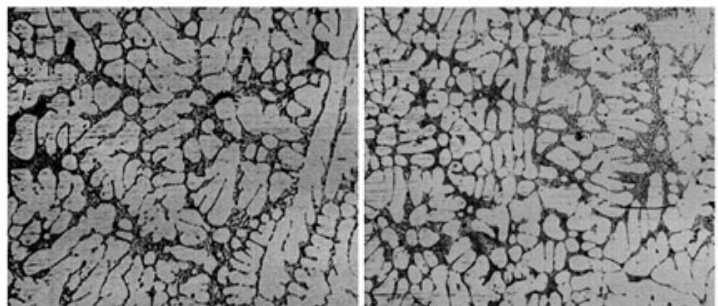

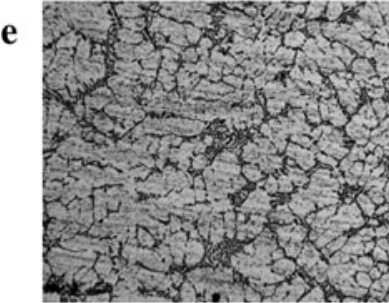

5 min

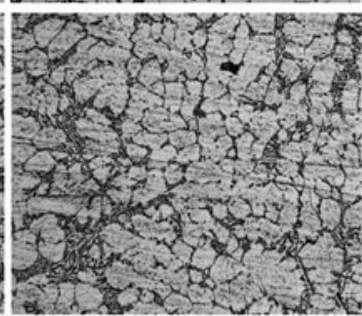

$15 \mathrm{~min}$

Fig. 3 Metallographic microstructure of A356 refined by Al-5Ti$0.25 \mathrm{C}-2 \mathrm{RE}$. A raw of images expressing material with the same composition addition, a column of images exhibiting the same

\section{Results and discussion}

\subsection{Grain refinement of $\mathrm{A} 356$ by $\mathrm{Al}-5 \mathrm{Ti}-0.25 \mathrm{C}-2 \mathrm{RE}$}

Figure 1 is the macrostructures of A356 with different addition levels of Al-5Ti-0.25C-2RE. Figure (1a) shows the largest equiaxial grains distributed homogeneously in A356 commercial alloy. When adding the master alloy into the A356, grain size decreases. A356 shows a poor refining

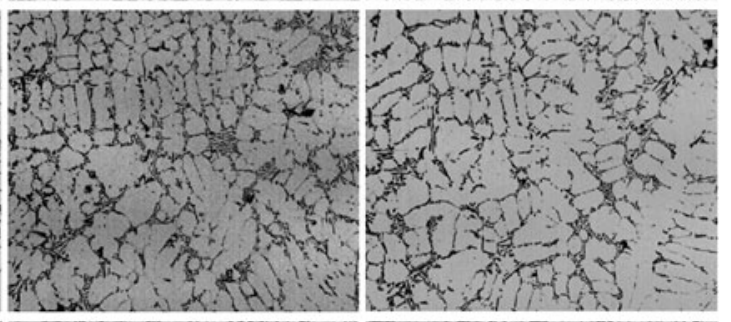

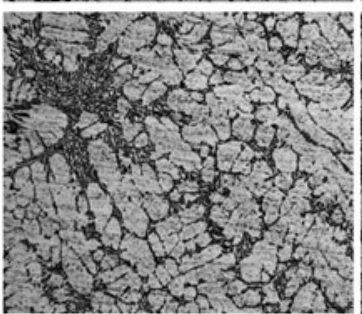

$30 \mathrm{~min}$

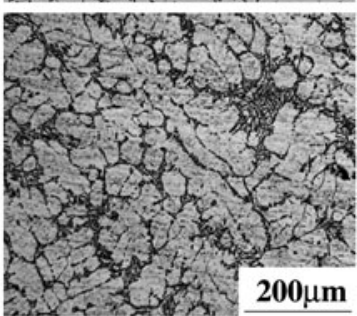

$60 \mathrm{~min}$ holding time, all images being the same magnification. a $3.0 \%$, b $2.0 \%$, c $1.0 \%$, d $0.5 \%$, and e $0 \%$

effect when the adding quantity of the master alloy is 0.5 or $1.0 \mathrm{wt} \%$, as shown in Fig. 1(b) and (c). Increasing the addition level up until to $3.0 \mathrm{wt} \%$, A356 can get a satisfactory refining effect, as shown in Fig. 1e.

Table 1 shows $\mathrm{BH}$ of commercial A356 refined by adding $\mathrm{Al}-5 \mathrm{Ti}-0.25 \mathrm{C}-2 \mathrm{RE}$, which indicates that the $\mathrm{BH}$ of A356 increases with decreasing grain size. The $\mathrm{BH}$ of A356 refined by 3.0 wt $\%$ Al-5Ti-0.25C-2RE increased by $16.9 \%$ compared with the initial commercial A356 alloy. 


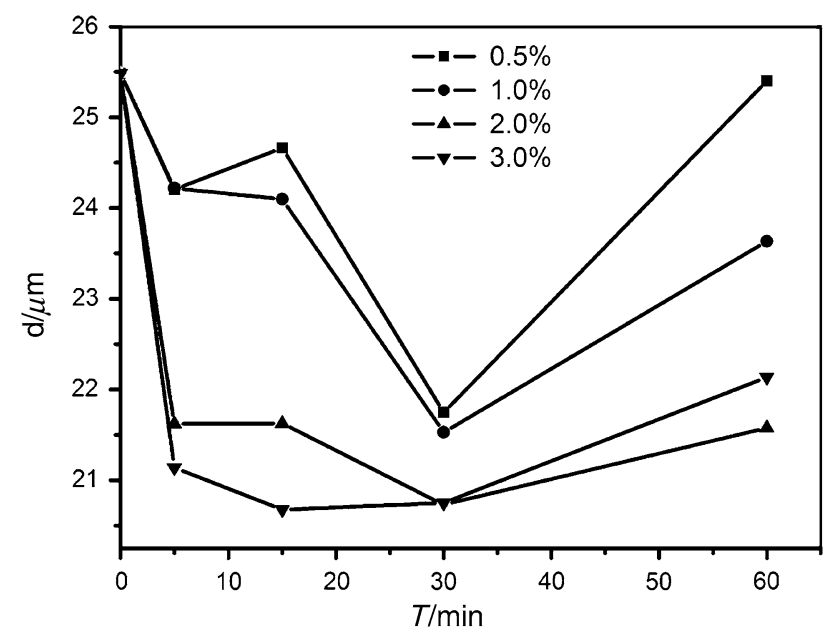

Fig. 4 Impact of addition level of Al-5Ti-0.25C-2RE and holding time on SDAS of A356

\subsection{Dendrite refinement of A356 by}

Al-5Ti-0.25C-2RE

Figure 2 shows the microstructure of A356 refined by Al-5Ti-0.25C-2RE. As shown in Fig. 2(a), cast A356 alloy without grain refiner shows long strip and coarse dendrite grains. When adding $3.0 \mathrm{wt} \% \mathrm{Al}-5 \mathrm{Ti}-0.25 \mathrm{C}-2 \mathrm{RE}$ master alloy into A356, the significant refinement of dendrite can be seen from Fig. 2(b). Long acicular eutectic silicon is replaced by short and pointillize silicon.

Figure 3 shows the refining effect of A356 with different addition levels of Al-5Ti-0.25C-2RE and different holding periods. SDAS was measured and calculated from

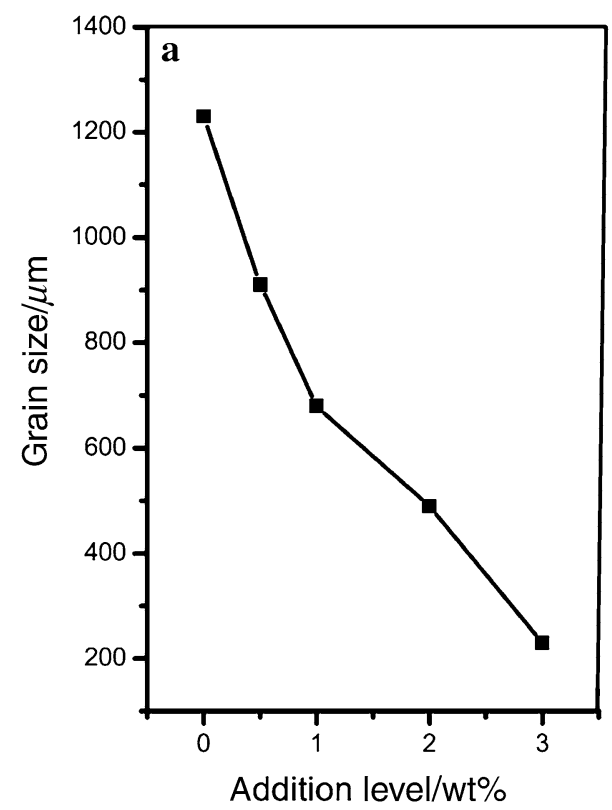

Fig. 3, and its developing trend is shown in Fig. 4. From Figs. 3 and 4, we can observe that, with a certain addition level, dendrite exhibits a weak refinement with $5 \mathrm{~min}$ holding time. Dendrite can get an optimal refining effect by increasing the holding time to $30 \mathrm{~min}$. When further increasing the holding time to $60 \mathrm{~min}$, refining shows a fading effect. Dendrite of A356 with $0.5 \mathrm{wt} \%$ master alloy shows the best refining effect by holding for $30 \mathrm{~min}$. Although dendrite can be further refined by increasing the master alloy, refining effect is not obvious when the addition amount of master is above $3.0 \mathrm{wt} \%$.

\subsection{Comparison of grain refinement and dendrite refinement}

Figure 5 shows the developing trend of SDAS and grain size. The comparison between grain refinement and dendrite refinement shows that SDAS can be refined from 25.482 to $21.748 \mu \mathrm{m}$ by addition $0.5 \mathrm{wt} \%$ master alloy, and SDAS is reduced by $14.7 \%$. When the master alloy is increased to $3.0 \mathrm{wt} \%$, SDAS is only reduced by $4.2 \%$ compared with alloy with $0.5 \mathrm{wt} \%$ master alloy. Grain size can only be refined from 1,230 to $910 \mu \mathrm{m}$ by addition of $0.5 \mathrm{wt} \%$ master alloy, so the refining effect is very poor. However, by further adding the master alloy to $3.0 \mathrm{wt} \%$, grain size is effectively refined to $230 \mu \mathrm{m}$. To sum up, although $0.5 \mathrm{wt} \%$ master alloy can effectively refine SDAS, it has a weak effect on grain size. Increasing the addition level, the grain can get a better refining effect, but the SDAS refinement has no obvious improvement.

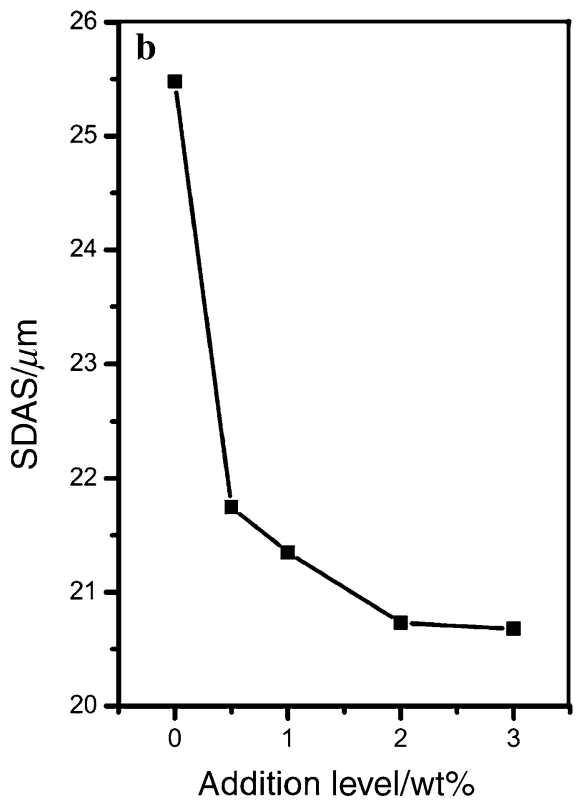

Fig. 5 Different refining effects of grain size (a) and SDAS (b) 


\subsection{Discussion}

Through the above analysis, it can be concluded that the grain and dendrite are refined in different ways and the refining mechanism is different.

In the grain refining process, $\mathrm{Al}-\mathrm{Ti}-\mathrm{C}$ master alloy releases $\mathrm{TiC}$ particles to the melt. As the crystal structure and lattice parameter of $\mathrm{TiC}$ are similar to $\alpha-\mathrm{Al}, \mathrm{TiC}$ can stimulate $\alpha-\mathrm{Al}$ nucleates effectively [13]. Nafisi and Banerji proposed that TiC particles are unstable in the melt in the way that they are easily transformed into $\mathrm{Al}_{4} \mathrm{C}_{3}$. As the structure of $\mathrm{Al}_{4} \mathrm{C}_{3}$ is hexagonal, and $\mathrm{Al}_{4} \mathrm{C}_{3}$ has a poor matching ability with $\alpha$-Al, which results in $\mathrm{TiC}$ loss its nucleation ability [14, 15]. In our previous experiment, the $\mathrm{Al}-5 \mathrm{Ti}-0.25 \mathrm{C}-2 \mathrm{RE}$ master alloy was used to refine pure aluminum, and a good refining effect was obtained with only $0.5 \mathrm{wt} \%$ master alloy. In the refining process of pure aluminum, $\mathrm{TiAl}_{3}$ and $\mathrm{Ti}_{2} \mathrm{Al}_{20} \mathrm{Ce}$ released $\mathrm{Ti}$ atoms to the melt. $\mathrm{Ti}$ atoms were easily segregated on the surface of $\mathrm{TiC}$, and a layer rich in $\mathrm{Ti}$ was formed. The layer can not only protect $\mathrm{TiC}$ from changing into $\mathrm{Al}_{4} \mathrm{C}_{3}$, but also promote the nucleation of $\alpha$-Al by peritectic reaction, and more detail was represented in Ref. [8]. When compared with the optimal addition level for pure aluminum, it is interesting to find that $0.5 \mathrm{wt} \%$ master alloy nearly has no effect on A356, as shown in Fig. 1(b). Mohanty and Gruzieski [16] proposed that the high content of $\mathrm{Si}$ in A356 is prone to react with $\mathrm{Ti}$ and formed a ternary Al-Ti-Si phase, which would lead to the loss of free $\mathrm{Ti}$ in the melt and damage the Ti-rich layer. Losing the protection of Ti-rich layer, TiC would change into $\mathrm{Al}_{4} \mathrm{C}_{3}$ easily and lose the nucleation precursor. For the newly formed $\mathrm{Al}-\mathrm{Ti}-\mathrm{Si}$ in pure $\mathrm{Al}$, it can react with the melt and promote the nucleation of $\alpha$-Al. However, because the nucleation temperature is very low [17], the nucleation is ineffective. All the factors referred above result in the weak refining effect of $0.5 \mathrm{wt} \%$ master alloy for A356. However, when increasing the addition level of master alloy, the refining effect becomes better, as shown in Fig. 1(e). The responsible reason is that the master alloy introduces much more newly free $\mathrm{Ti}$ to the melt. Meanwhile, $\mathrm{Ti}_{2} \mathrm{Al}_{20} \mathrm{Ce}$ releases $\mathrm{Ti}$ and $\mathrm{Al}_{4} \mathrm{Ce}$ to the melt. $\mathrm{Al}_{4} \mathrm{Ce}$ is also an effective nucleation phase for $\alpha-\mathrm{Al}$, so the refining effect for $\mathrm{A} 356$ becomes better with the increasing of master alloy, as shown in Fig. 1.

Casting temperature, cooling rate, alloy composition, and its own properties are the main factors for SDAS in the solidification process. Chen and Kattamis [18] proposed that SDAS can be expressed by

$\lambda=5.5\left(M t_{\mathrm{f}}\right)^{1 / 3}$

$M=\frac{-\Gamma D_{\mathrm{L}} \ln \left(C_{\mathrm{L}} / C_{0}\right)}{m_{\mathrm{L}}(1-k)\left(C_{0}-C_{\mathrm{L}}\right)}$,

where $t_{\mathrm{f}}$ is the local solidification time, $\Gamma$ is the GibbsThompson coefficient, $D_{\mathrm{L}}$ is the solute diffusion coefficient in the liquid, $C_{\mathrm{L}}$ is the liquid phase concentration, $C_{0}$ is the original concentration of the liquid, $m_{\mathrm{L}}$ is slope of liquid, and $k$ is the equilibrium partition coefficient.

As shown in Eqs. (1) and (2), SDAS is mainly influenced by $M$ and the local solidification time $t_{\mathrm{f}} . M$ is affected by alloy composition and diffusion coefficient. When keeping the alloy composition at a certain, $\lambda$ is mainly affected by $D_{\mathrm{L}}$ and some others factors that are related to $D_{\mathrm{L}}$, such as casting temperature and cooling rate. In this experiment, alloys are casted and cooled in the same condition, so $M$ has little influence on SDAS. In the refining process, $\mathrm{Ti}_{2} \mathrm{Al}_{20} \mathrm{Ce}$ releases $\mathrm{La}$ and $\mathrm{Ce}$ to the melt, and the atomic radiuses of $\mathrm{La}$ and $\mathrm{Ce}$ are 0.274 and $0.270 \mathrm{~nm}$, respectively. However, $\mathrm{Al}$ atomic radius is only $0.182 \mathrm{~nm}$, so La and Ce are easily supplanted to the interdendrite region. The constitutional supercooling by the segregation of rare earth can effectively reduce the local solidification time $t_{\mathrm{f}}$, so little addition of master alloy can effectively refine the SDAS. At the same time, Ti can also make an effort in confining the growth of dendrite [19]. That is the reason why $0.5 \mathrm{wt} \%$ master alloy has a weak effect on grain refinement but can effectively refine the dendrite. The poor dendrite refinement by increasing the addition of master alloy is because the segregation of rare earth reached a saturation state. The newly added Ti can promote the refining process, but the effect is very weak. Thus, further increasing master alloy addition has no significant effect for dendrite refining, as shown in Fig. 3.

\section{Conclusion}

A small amount $(0.5 \mathrm{wt} \%)$ of $\mathrm{Al}-5 \mathrm{Ti}-0.25 \mathrm{C}-2 \mathrm{RE}$ is weak to the grain refining effect, but when increasing the addition level to $3.0 \mathrm{wt} \%$, A356 can get a satisfactory grain refining effect. $0.5 \mathrm{wt} \% \mathrm{Al}-5 \mathrm{Ti}-0.25 \mathrm{C}-2 \mathrm{RE}$ can effectively refine the SDAS; while further increasing the addition level, there is no significant influence for dendrite refinement. Grain and dendrite are refined in different ways, and dendrite can get the optimal refining effect more easily than grain.

Acknowledgments This project was financially supported by the National Natural Science Foundation of China (No. 51174177).

Open Access This article is distributed under the terms of the Creative Commons Attribution License which permits any use, distribution, and reproduction in any medium, provided the original author(s) and the source are credited.

\section{References}

[1] Wang X, Chen GQ, Li B, Wu LM, Jiang DM. Effects of Sc, Zr and $\mathrm{Ti}$ on the microstructure and properties of Al alloys with high Mg content. Rare Met. 2010;29(1):66. 
[2] Zhao HL, Zhou ZX, Liu XD, Guan SK. Influence of $\mathrm{Mg}_{3} \mathrm{~N}_{2}$ powder on microstructures and mechanical properties of AZ31Mg alloy. J Cent S Univ Technol. 2008;15(4):459.

[3] Easton M, Davidson C, Stjohn D. Effect of alloy composition on the dendrite arm spacing of multicomponent aluminum alloys. Metall Mater Trans A. 2010;41(6):1528.

[4] Li W, Liao HC, Lu B, Xi X. The effect of RE on Sr modifying Al-13\% Si alloy. Foundry. 2009;58(4):364.

[5] Li YL, Feng HK, Cao FR, Cheng YB, Gong LY. Effect of high density ultrasonic on the microstructure and refining property of Al-5Ti-0.25C grain refiner alloy. Metall Mater Trans A. 2008; 487(1):518.

[6] Kumar GS, Murty BS, Chakraborty M. Development of Al-Ti$\mathrm{C}$ grain refiners and study of their grain refining efficiency on $\mathrm{Al}$ and Al-7Si alloy. J Alloy Compd. 2005;396(1-2):143.

[7] Li DW, Ding YZ, Zhe LW, Li GH, Wei S, Yong LC. The refinement effect of Al-Ti-C-RE master alloy prepared by adding $\mathrm{Ce}_{2} \mathrm{O}_{3}$ on pure Al. Adv Mater Res. 2010;139:227.

[8] Zhao H, Song Y, Li M, Guan S. Grain refining efficiency and microstructure of Al-Ti-C-RE master alloy. J Alloy Compd. 2010;508(1):206.

[9] Birol Y. A novel Al-Ti-B alloy for grain refining Al-Si foundry alloys. J Alloy Compd. 2009;486(1-2):219.

[10] Ni H, Sun BD, Jiang HY, Ding WJ. Effect of RE on SDAS of A356 alloy. Chin J Nonferrous Metals. 2002;12(5):940.

[11] Prasada RAK, Das K, Murty BS, Chakraborty M. Microstructural features of as-cast A356 alloy inoculated with $\mathrm{Sr}, \mathrm{Sb}$ modifiers and Al-Ti-C grain refiner simultaneously. Mater Lett. 2008;62(2):273.
[12] Guan RG, Cao FR, Chen LQ, Li JP, Wang C. Dynamical solidification behaviors and microstructural evolution during vibrating wavelike sloping plate process. J Mater Process Technol. 2009;209(5):2592.

[13] Karantzalis A, Lekatou A, Georgatis E, Tsiligiannis T, Mavros $\mathrm{H}$. Solidification observations of dendritic cast Al alloys reinforced with TiC particles. J Mater Eng Perform. 2010;19(9): 1268.

[14] Nafisi S, Ghomashchi R. Grain refining of conventional and semi-solid A356 Al-Si alloy. J Mater Process Technol. 2006;174(1-3):371.

[15] Banerji A, Reif W. Metallographic investigation of TiC nucleants in the newly developed Al-Ti-C grain refiner. J Mater Sci. 1994;29(7):1958.

[16] Mohanty PS, Gruzieski JE. Grain refinement of aluminium by TiC. Scr Metall Mater. 1994;31(2):179.

[17] Chen XG, Fortier M. TiAlSi intermetallic formation and its impact on the casting processing in $\mathrm{Al}-\mathrm{Si}$ alloys. J Mater Process Technol. 2010;210(13):1780.

[18] Chen M, Kattamis TZ. Dendrite coarsening during directional solidification of Al-Cu-Mn alloys. Mater Sci Eng A. 1998; 239-247:239.

[19] Zhang Z, Hosoda S, Kim IS, Watanabe Y. Grain refining performance for $\mathrm{Al}$ and $\mathrm{Al}-\mathrm{Si}$ alloy casts by addition of equalchannel angular pressed Al-5 mass\% Ti alloy. Mater Sci Eng A. 2006;425(1-2):55. 